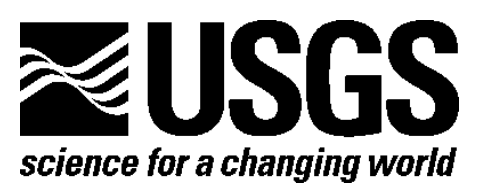

\title{
Summarizing Components of U.S. Department of the Interior Vulnerability Assessments to Focus Climate Adaptation Planning
}

By Laura M. Thompson, Michelle D. Staudinger ${ }^{1}$, and Shawn L. Carter

Open-File Report 2015-1110

U.S. Department of the Interior

U.S. Geological Survey 


\section{U.S. Department of the Interior \\ SALLY JEWELL, Secretary}

\section{U.S. Geological Survey \\ Suzette M. Kimball, Acting Director}

U.S. Geological Survey, Reston, Virginia: 2015

For more information on the USGS-the Federal source for science about the Earth,
its natural and living resources, natural hazards, and the environment-visit
http://www.usgs.gov/ or call 1-888-ASK-USGS (1-888-275-8747).
For an overview of USGS information products, including maps, imagery, and publications,
visit http://www.usgs.gov/pubprod/.

Any use of trade, firm, or product names is for descriptive purposes only and does not imply endorsement by the U.S. Government.

Although this information product, for the most part, is in the public domain, it also may contain copyrighted materials as noted in the text. Permission to reproduce copyrighted items must be secured from the copyright owner.

Suggested citation:

Thompson, L.M., Staudinger, M.D., and Carter, S.L., 2015, Summarizing components of U.S. Department of the Interior vulnerability assessments to focus climate adaptation planning: U.S. Geological Survey Open-File Report 2015-1110, 14 p., http://dx.doi.org/10.3133/ofr20151110.

ISSN 2331-1258 (online) 


\section{Contents}

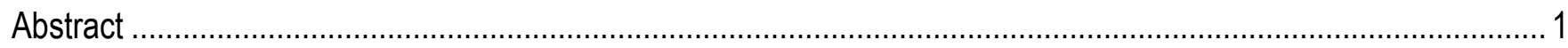

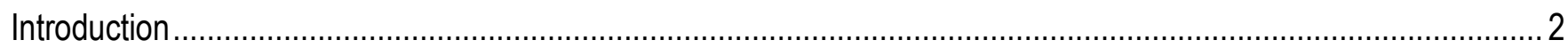

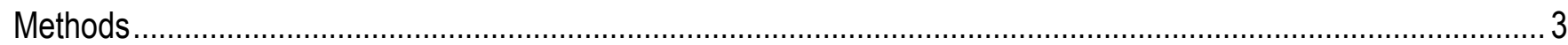

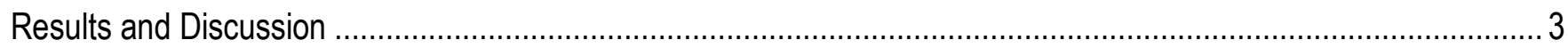

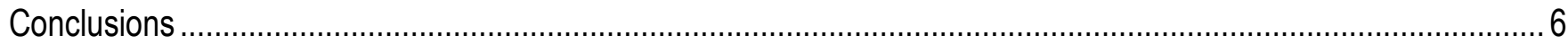

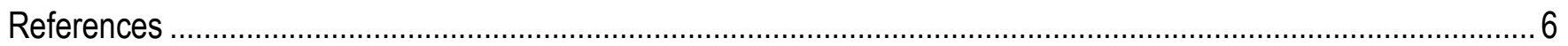

Appendix A. Text distributed to DOI agencies for the initial data call on climate change vulnerability

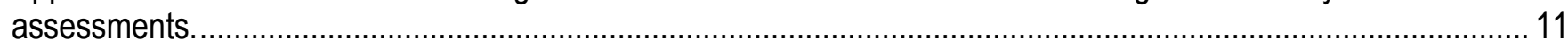

Appendix B. Questionnaire used for the supplemental DOI vulnerability assessment survey.............................. 13

\section{Figures}

1. The frequency that each of the three vulnerability components were assessed by projects in the DOI data call.

2. The total number of projects in the DOI data call that assessed 0 VA components, 1 VA component, 2 VA components, or all 3 components

\section{Tables}

1. Example responses from project investigators and how they were subsequently categorized based on the three vulnerability components (exposure, sensitivity, and adaptive capacity).....

2. The total number of projects in the DOI data call that addressed one or more focal resources or threats and the total number that assessed either exposure, sensitivity, exposure and sensitivity, exposure and sensitivity and adaptive capacity, or could not be classified. 


\title{
Summarizing Components of U.S. Department of the Interior Vulnerability Assessments to Focus Climate Adaptation Planning
}

\author{
By Laura M. Thompson ${ }^{1}$, Michelle D. Staudinger ${ }^{1,2}$, and Shawn L. Carter ${ }^{1}$
}

\begin{abstract}
A secretarial order identified climate adaptation as a critical performance objective for future management of U.S. Department of the Interior (DOI) lands and resources in response to global change. Vulnerability assessments can inform climate adaptation planning by providing insight into what natural resources are most at risk and why. Three components of vulnerability — exposure, sensitivity, and adaptive capacity—were defined by the Intergovernmental Panel on Climate Change (IPCC) as necessary for identifying climate adaptation strategies and actions. In 2011, the DOI requested all internal bureaus report ongoing or completed vulnerability assessments about a defined range of assessment targets or climaterelated threats. Assessment targets were defined as freshwater resources, landscapes and wildlife habitat, native and cultural resources, and ocean health. Climate-related threats were defined as invasive species, wildfire risk, sea-level rise, and melting ice and permafrost. Four hundred and three projects were reported, but the original DOI survey did not specify that information be provided on exposure, sensitivity, and adaptive capacity collectively as part of the request, and it was unclear which projects adhered to the framework recommended by the IPCC. Therefore, the U.S. Geological Survey National Climate Change and Wildlife Science Center conducted a supplemental survey to determine how frequently each of the three vulnerability components was assessed. Information was categorized for 124 of the 403 reported projects ( 30.8 percent) based on the three vulnerability components, and it was discovered that exposure was the most common component assessed ( 87.9 percent), followed by sensitivity (68.5 percent) and adaptive capacity (33.1 percent). The majority of projects did not fully assess vulnerability; projects focused on landscapes/wildlife habitats and sea-level rise were among the minority that simultaneously addressed all three vulnerability components. To maintain consistency with the IPCC definition of vulnerability, DOI may want to focus initial climate adaptation planning only on the outcomes of studies that comprehensively address vulnerability as inclusive of exposure, sensitivity, and adaptive capacity. Although the present study results are preliminary and used an unstructured survey design, they illustrate the importance of a comprehensive and consistent vulnerability definition and of using information on vulnerability components in DOI surveys to ensure relevant data are used to identify adaptation options.
\end{abstract}

\footnotetext{
${ }^{1}$ U.S. Geological Survey, National Climate Change and Wildlife Science Center, Reston, VA 20192-0001

${ }^{2}$ DOI Northeast Climate Science Center, University of Massachusetts, Amherst, MA 01003-9297
} 


\section{Introduction}

Climate change profoundly affects a multitude of resources in the United States, and future projections suggest these trends are likely to continue (Staudinger and others, 2012). A coordinated response to climate change effects is important for the U.S. Department of the Interior (DOI), which manages 20 percent of U.S. lands, provides water resources for approximately 10 percent of the U.S. population, and is responsible for conserving plant, fish, and wildlife populations, and tribal and cultural resources (U.S. Bureau of Reclamation, 2014; U.S. Department of the Interior, 2014). Climate adaptation is the process of preparing for and coping with the impacts of climate change (Glick and others, 2009, 2011) and has been identified by the Secretary of Interior (2009) as a high priority for the DOI. Meaningful adaptation strategies can only be implemented when the relative vulnerabilities of resources to future environmental changes are understood. Vulnerability assessments (VAs) provide knowledge about resources likely to be affected by climate change and information on why those resources are vulnerable (Glick and others, 2011). Therefore, VAs are important for prioritizing management actions and developing appropriate adaptation responses and alternatives (Glick and others, 2011). The Intergovernmental Panel on Climate Change (IPCC) defines vulnerability as three distinct components: (1) exposure: magnitude and rate of climate change a resource is likely to experience, (2) sensitivity: characteristics that mediate tolerance to climate change of a particular resource, and (3) adaptive capacity: the inherent ability of the target to moderate the impacts of climate change (IPCC 2007, Glick and others, 2011).

The simultaneous assessment of all three vulnerability components provides a comprehensive and rigorous framework for climate adaptation planning. VAs use projections of changes in climate variables (for example, temperature and precipitation), sea-level, or hydrology to provide insight into the potential risk a resource has to climate change drivers, in addition to providing a suite of qualitative and quantitative techniques that can determine how responsive a particular resource(s) is to projected changes (for example, response models; Glick and others, 2011). VAs also identify intrinsic traits or external factors that allow a resource to adapt to future climate changes (Glick and others, 2011). Managers can then identify the options most likely to reduce exposure and sensitivity, and increase adaptive capacity, and implement them through changes in practice or policy (Glick and others 2011).

In 2011, the DOI set a high priority performance goal in which 50 percent of the nation's resources would be assessed for climate change vulnerability by the end of 2012. As a measure of progress toward reaching that goal, information on completed and ongoing VAs was requested from the DOI, including the Bureau of Land Management (BLM), Bureau of Reclamation (BOR), National Park Service (NPS), U.S. Fish and Wildlife Service (USFWS), and U.S. Geological Survey (USGS). The USGS surveyed DOI bureaus in January 2011 for VA projects that addressed a specific range of resources (freshwater supplies, landscapes and wildlife habitat, native and cultural resources, ocean health) or climate-related threats (invasive species, wildfire risk, sea-level rise, and melting ice/permafrost). These conservation and management endpoints were identified by the DOI as priorities for all bureaus and were therefore included in the survey. Other data collected by the survey included the project title and location, Landscape Conservation Cooperative (LCC), start and end dates, and the principal investigator's contact information (Appendix A). The survey resulted in 403 submissions from five agencies; 12 from NPS, 10 from BOR, 189 from USGS, 51 from BLM, and 141 from USFWS; across 21 LCC regions. 
The large number and diversity of VA projects suggests the DOI was progressing towards the high priority performance goals. However, the initial survey did not request all three vulnerability components as a requirement of the reporting process (Appendix A) and projects addressing single vulnerability components may have been reported. It was suggested by the IPCC (2007), and in a recently published guide on best practices for conducting VAs (Glick and others, 2011), that simultaneous assessments of exposure, sensitivity, and adaptive capacity are important for guiding climate adaptation planning. Therefore, the goal of this study was to determine the proportion of projects from the initial survey using the comprehensive framework presented by the IPCC (2007), provide a detailed assessment of DOI projects focused on potentially vulnerable resources, and identify priority areas for climate adaptation planning.

\section{Methods}

The USGS National Climate Change and Wildlife Science Center (NCCWSC) conducted a supplemental survey on the initial vulnerability assessment data call to identify DOI projects that incorporate any of the three VA components (exposure, sensitivity, and adaptive capacity). Contact information submitted as part of the DOI survey was used to acquire details on each study by interviewing project investigators over the phone and through email. Information was also obtained by evaluating online reports acquired from project investigators. Project investigators were contacted in the order that they appeared in the initial survey: BLM, BOR, NPS, USFWS, and USGS. Each agency pre-screened the initial DOI survey prior to the supplemental survey, and a large number of projects were classified as information-gathering studies (for example, monitoring, modeling) by the USGS $(n=109)$; therefore investigators from those projects were not contacted. Open-ended questions (Appendix B) were used to collect data because objectives varied considerably between projects, and VA components may not have been a given study's focus. Additionally, not all participants were familiar with the terms (exposure, sensitivity, and adaptive capacity), so questions related to climate projections and response models were included to increase the ability of respondents to determine whether or not vulnerability components were targeted in the study. Responses to questions 1, 2, 5, 6, and 7 (Appendix B) were used to determine if each of the three VA components was considered. Projects in which a sufficient amount of detail was obtained for evaluating whether exposure, sensitivity, and adaptive capacity were individually or jointly considered and were binned based on the presence of those three components (Table 1), as well as on the focal resources and types of climate-related threats identified as interests for the DOI. Inquiries were also made about the spatial footprint of assessments (questions 3 and 4 in Appendix B) to determine whether the VAs could be mapped, which would allow for identification of geographic gaps in assessment activity and areas concerned with climate adaptation that could be prioritized.

\section{Results and Discussion}

After omitting information-gathering studies, sufficient information was obtained to categorize 124 of the remaining 294 projects (42.2 percent) based on the three components of vulnerability. A total of 161 of the 294 projects (54.8 percent) could not be categorized due to limited or nonexistent information; these cases occurred when a project investigator could not be reached or when the primary contact did not have detailed information readily available. Nine projects (3.1 percent) were removed prior to data collection because they were identified as duplicate submissions or as projects that had not been funded or begun by the start of the initial 
survey. The VAs summarized in the supplemental survey could not be mapped because in many cases the geospatial information was vague or incomplete. For example, many projects simply described the study area as "millions of acres" or did not provide quantitative units of scale. The inability to summarize geospatial information was partially a result of open-ended survey questions, which made mapping difficult. Additionally, not all project investigators had detailed geospatial information readily available.

Of the remaining 124 projects where adequate information allowed the three components of vulnerability to be evaluated, exposure was the most commonly assessed component ( $n=109$, 87.9 percent). In 34 of these 109 projects (31.2 percent), exposure was the only component of vulnerability assessed; 34 (31.2 percent) assessed exposure in conjunction with sensitivity; and 41 (37.6 percent) assessed exposure, sensitivity, and adaptive capacity simultaneously (Figs. 1 and 2). In 75 of the 85 projects that assessed sensitivity (88.2 percent), exposure or exposure and adaptive capacity were also assessed as part of their study design (Figs. 1 and 2). Adaptive capacity was assessed in the fewest studies overall, and only when both exposure and sensitivity were also considered ( $n=41,33.1$ percent; Figs. 1 and 2$)$.

A total of 122 out of the 124 projects identified a focal resource. Landscapes/wildlife habitat ( 72 projects) and freshwater supplies ( 25 projects) were the most commonly listed resources, while ocean health (4 projects) and native/cultural resources (1 project) were the least common (Table 2). There were 21 studies that identified more than one focal resource (Table 2); 15 (71.4 percent) of those included freshwater resources and landscapes/wildlife habitat; four (19.0 percent) included landscapes/wildlife habitat and native/cultural resources; one (4.8 percent) included landscapes/wildlife habitat and ocean health; and one ( 4.8 percent) included freshwater supplies and native/cultural resources. All of the projects related to freshwater supplies assessed either exposure $(n=24,96.0$ percent) or sensitivity ( $n=1,4.0$ percent) independently. Projects addressing landscapes/wildlife habitat, native/cultural resources, ocean health, and multiple focal resources ( $n=75,60.5$ percent) usually considered two or more vulnerability components, which were most often exposure and sensitivity (Table 2 ).

Of the 70 VA projects that identified a focal climate-related threat, sea-level rise was the most common $(n=47,67.1$ percent $)$; invasive species $(n=6,8.6$ percent), wildfire risk $(n=5$, 7.1 percent), and melting ice/permafrost ( $n=1,1.4$ percent) were less common. In 11 projects two or more focal climate-related threats were identified; four of those ( 36.4 percent) included invasive species and wildfire risk, three (27.3 percent) included invasive species and sea-level rise, one (9.1 percent) included sea-level rise and melting ice/permafrost, one (9.1 percent) included invasive species, wildfire risk, and melting ice/permafrost, and two (18.2 percent) included all four climate-related threats (Table 2). The majority of projects that addressed a climate-related focal threat also assessed multiple components of vulnerability - exposure and sensitivity $(n=24,34.3$ percent) and all three components simultaneously $(n=34$, 48.6 percent) — when determining vulnerability (Table 2 ).

The comprehensive assessment of vulnerability in the supplemental survey was greatest for projects addressing landscapes/wildlife habitat and sea-level rise, with the majority of projects assessing two (exposure and sensitivity) or all three (exposure, sensitivity, and adaptive capacity) vulnerability components. However, projects addressing landscapes/wildlife habitat were also the most commonly reported resources, and sea-level rise was the most commonly reported climate-related threat (Table 2). This skew in data related to the categories of the reported projects may explain why a larger number of comprehensive assessments existed only in those categories. Because projects that simultaneously assess all three vulnerability 
components are the most useful for understanding why a particular target is vulnerable and for identifying adaptation options, our findings suggest landscapes/wildlife habitat as the most appropriate for the DOI to focus on in initial climate adaptation planning. Additionally, the large number of comprehensive vulnerability assessments about sea-level rise suggests it is a climaterelated threat on which the DOI could also focus adaptation efforts.

A small number of studies addressed native/cultural resources, ocean health, invasive species, wildfire risk, and melting ice/permafrost (Table 2). Those resources and threats are under-represented in the supplemental survey because information could not be acquired for a large number of projects. The only exception was for ocean health and melting ice/permafrost, which represented $<10$ percent of the initial DOI survey. Therefore, if DOI is to adequately assess the vulnerability of ocean health and melting ice/permafrost to climate change effects, additional studies of vulnerability are necessary.

Many projects concerned with freshwater supplies focused only on exposure. A potential explanation is that many projects were not designed as vulnerability assessments and did not incorporate the framework used by the IPCC. For example, the Water Resource Inventory and Assessment program conducted by the USFWS was designed to inventory information on potential climate change (exposure) and assess potential needs related to water resources (U.S. Fish and Wildlife Service, 2012), but is not specifically designed to assess the sensitivity or adaptive capacity of water resources. Other projects also exclude certain vulnerability components because they were conducted for research purposes and focus on the sensitivity of a resource. However, those efforts still collect important information that could inform VAs and climate adaptation planning. It is important to note that a key VA guidebook (Glick and others, 2011) was released at approximately the same time the data call was executed, so definitions of climate change vulnerability and vulnerability components may have been unavailable to DOI scientists until recently. Finally, the exclusion of adaptive capacity may have occurred because it is often poorly understood and can be difficult to measure, especially in the context of evolutionary adaptation (Manel and others, 2012).

One limitation present in the study was the survey's unstructured design, which was used to acquire information on vulnerability assessments. Survey questions related to each study's assessment of exposure, sensitivity, and adaptive capacity were open-ended questions, as opposed to closed-ended questions with fixed responses. This survey approach was chosen to obtain insights on whether or not the vulnerability components were assessed even when respondents were unfamiliar with the concepts; unfortunately, this enabled the potential for bias and subjectivity to affect the results. Because the study design did not use a structured survey method, results should be viewed as preliminary. Other noteworthy limitations include concerns that the percentage of VA components assessed may have been underestimated due to difficulties in defining and gauging adaptive capacity (Adger and Vincent, 2005; Williams and others, 2008), and geospatial coverage of VAs in this survey could not be accurately assessed. Future research can minimize potential limitations by using a structured survey design with fixed, welldefined responses to determine how frequently exposure, sensitivity, and adaptive capacity are used in DOI vulnerability assessments. The Climate Registry on the Assessment of Vulnerability (CRAVe; https://nccwsc.usgs.gov/crave/) is a recent and ongoing project administered by the NCCWSC and EcoAdapt and was designed to capture metadata on VAs, including the three vulnerability components, and may provide a source for structured survey work in the future. 


\section{Conclusions}

The results of this supplemental survey provide insights into the Nation's progress toward understanding vulnerability to climate change. Because the majority of the 124 projects that furnished information ( 90.3 percent) reported a project completion date no later than the fourth quarter of 2014, the DOI should possess sufficient information to facilitate climate adaptation planning. This survey provides the DOI with information on essential resources and climaterelated threats that indicate where initial adaptation efforts can be focused, as well as information on resources and climate-related threats that indicate where additional assessment work could be beneficial prior to exercising management options.

Ongoing initiatives, such as CRAVe, can strengthen future vulnerability studies by showcasing new methods and techniques as they become available. Studies entered into CRAVe may have benefited from recently published guides on vulnerability assessment (for example, Glick and others, 2011) that were unavailable during the initial DOI VA data call. This project also incorporates studies funded by the newly established LCCs (2009-present) and the DOI Climate Science Centers (2010-present) that include vulnerability assessments as priorities in their strategic science plans and funding announcements. CRAVe can also help evaluate progress toward a consistent and comprehensive definition of adaptive capacity. Finally, CRAVe has incorporated a strategic approach for determining the spatial footprint of VA projects, which can help identify geographic gaps alongside gaps in assessed resources.

\section{References}

Adger, W. N. and Vincent, Katharine, 2005, Uncertainty in adaptive capacity: Comptes Rendus Geoscience, v. 337, no. 4, p. 399-410. [Also available at http://dx.doi.org/10.1016/j.crte.2004.11.004.]

Glick, Patty, Staudt, Amanda, and Stein, B.A., 2009, A new era for conservation-Review of climate change adaptation literature: Washington, D.C., National Wildlife Federation, 69 p. [Also available at https://www.nwf.org/pdf/Reports/NWFClimateChangeAdaptationLiteratureReview.pdf.]

Glick, Patty, Stein, B.A., and Edelson, N. A., eds., 2011, Scanning the conservation horizon-A guide to climate change vulnerability assessment: Washington, D.C., National Wildlife Federation, 168 p. [Also available at http://www.nwf.org/ /media/pdfs/globalwarming/climate-smart-conservation/nwfscanningtheconservationhorizonfinal92311.ashx.]

Manel, Stéphanie; Gugerli, Felix; Thuiller, Wilfred; Alvarez, Nadir; Legendre, Pierre; Holderegger, Rolf; Gielly, Ludovic; Taberlet, Pierre; and IntraBioDiv Consortium, 2012, Broad-scale adaptive genetic variation in alpine plants is driven by temperature and precipitation: Molecular Ecology, v. 21, no. 15, p. 3729-3738. [Also available at http://dx.doi.org/10.1111/j.1365-294x.2012.05656.x.]

Parry, M.L., Canziani, O.F., Palutikof, J.P., van der Linden, P.J., and Hanson, C.E., eds., 2007, Climate change 2007-Impacts, adaptation, and vulnerability-Contribution of Working Group II to the fourth assessment report of the Intergovernmental Panel on Climate Change: Cambridge, U.K., Cambridge University Press, 976 p. [Also available at 
http://www.ipcc.ch/publications_and_data/publications_ipcc_fourth_assessment_report_wg2_r eport_impacts_adaptation_and_vulnerability.htm.]

Secretary of the Interior, 2009, Addressing the impacts of climate change on America's water, land, and other natural and cultural resources: Washington, D.C., Department of the Interior, order no. 3289; 4 p. [Also available at http://www.doi.gov/whatwedo/climate/cop15/upload/SecOrder3289.pdf.]

Staudinger, M. D., Grimm, N.B., Staudt, Amanda, Carter, S.L., Chapin, F.S., III, Kareiva, Peter, Ruckelshaus, Mary, and Stein, B.A., 2012, Impacts of climate change on biodiversity, ecosystems, and ecosystem services-Technical input to the 2013 National Climate Assessment - Cooperative report to the 2013 National Climate Assessment: Washington, D.C., United States Global Change Research Program, Federal Government series report, 296 p., accessed November 17, 2013, at http://pubs.er.usgs.gov/publication/70039460.

U.S. Bureau of Reclamation (BOR), 2014, Reclamation-Managing water in the West - Climate change adaptation strategy: Washington, D.C., U.S. Bureau of Reclamation, 50 p., accessed February 13, 2015, at http://www.usbr.gov/climate/docs/ClimateChangeAdaptationStrategy.pdf.

U.S. Department of Interior (DOI), 2014, Department of the Interior climate change adaptation plan: Washington, D.C., Department of the Interior, accessed February 13, 2015, at http://www.doi.gov/greening/sustainability_plan/upload/2014_DOI_Climate_Change_Adaptat ion_Plan.pdf.

U.S. Fish and Wildlife Service (USFWS), 2012, Water resource inventory and assessment (WRIA) effort—Natural Resource Program Center: National Wildlife Refuge System, U.S. Fish and Wildlife Service Fact Sheet, January 2012; 2 p. [Also available at http://www.fws.gov/refuges/NaturalResourcePC/pdfs/FY2012_NRPC_WRIA_Fact_Sheet.pdf.

Williams, S. E., Shoo, L.P., Isaac, J.L., Hoffmann, A.A., and Langham, Gary, 2008, Towards an integrated framework for assessing the vulnerability of species to climate change: PloS Biology, v. 6, no. 12, p. 2621-2626. [Also available at http://journals.plos.org/plosbiology/article?id=10.1371/journal.pbio.0060325.] 


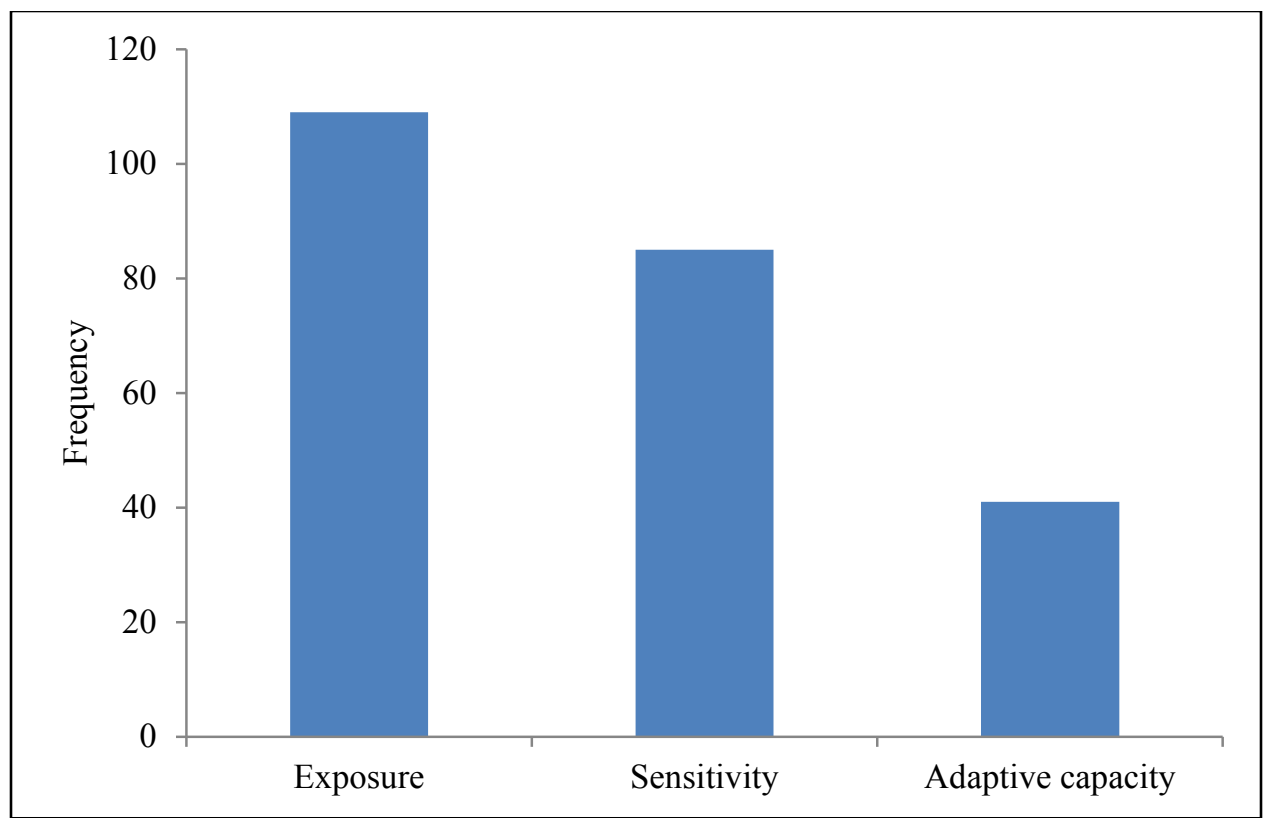

Figure 1. The frequency that each of the three vulnerability components (exposure, sensitivity, and adaptive capacity) were assessed by projects $(n=124)$ in the DOI data call.

Note: A large percentage (64.5 percent) of projects fall into 2 or more categories.

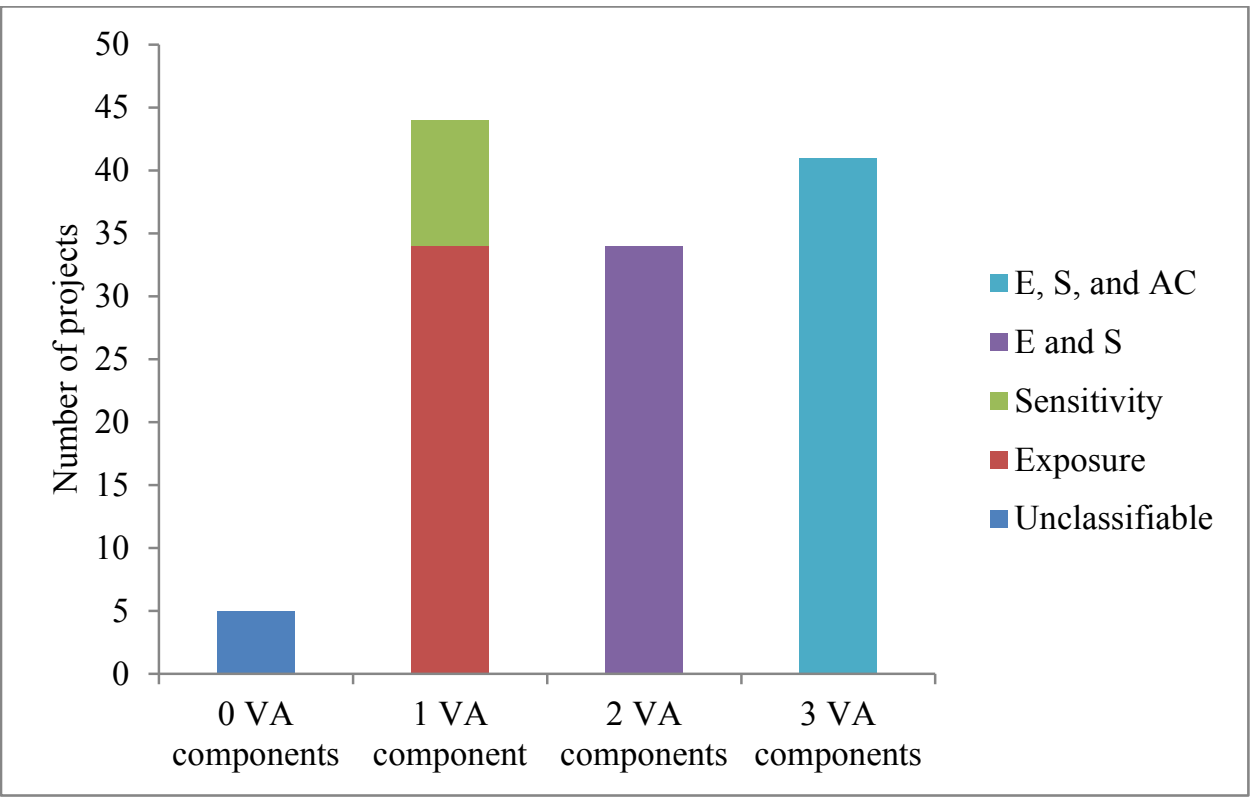

Figure 2. The total number of projects in the DOI data call $(n=124)$ that assessed 0 VA components (unclassifiable), 1 VA component (either exposure (E) or sensitivity (S)), 2 VA components ( $E$ and $S)$, or all 3 components (E, S, and adaptive capacity (AC)).

Note: No studies assessed only adaptive capacity, or the following combinations of two components: sensitivity and adaptive capacity, or exposure and adaptive capacity. 
Table 1. Example responses from project investigators and how they were subsequently categorized based on the three vulnerability components (exposure, sensitivity, and adaptive capacity).

\begin{tabular}{lcc}
\hline \multicolumn{1}{c}{ Agency and project title } & Exposure & Sensitivity \\
\hline $\begin{array}{l}\text { USFWS - Water Resource Inventory } \\
\text { and Assessment }\end{array}$ & $\begin{array}{c}\text { Explored historical temperature, } \\
\text { precipitation, and stream flow } \\
\text { trends and starting to look at future } \\
\text { climate projections }\end{array}$ & $\begin{array}{c}\text { Determined whether collared lynx } \\
\text { preferred areas with snow cover }\end{array}$ \\
$\begin{array}{l}\text { BLM - Radio Collaring of Canada } \\
\text { Lynx }\end{array}$ & $\begin{array}{c}\text { Considering a suite of sea-level rise } \\
\text { scenarios and frequency of storms }\end{array}$ & $\begin{array}{c}\text { Identifying nesting needs for piping } \\
\text { plover }\end{array}$ \\
$\begin{array}{l}\text { USGS - Determine vulnerability of } \\
\text { piping plover on Atlantic coast } \\
\text { beaches }\end{array}$ & $\begin{array}{c}\text { Incorporated downscaled climate } \\
\text { projections into a suite of climate } \\
\text { NPS/USGS - Impacts of climate } \\
\begin{array}{l}\text { change on Karner blue butterfly } \\
\text { habitats }\end{array}\end{array}$ & $\begin{array}{c}\text { Identified future habitat shifts from } \\
\text { the species distribution models }\end{array}$ \\
\hline
\end{tabular}


Table 2. The total number of projects in the DOI data call that addressed one or more focal resources or threats and the total number that assessed either exposure $(E)$, sensitivity $(S)$, exposure and sensitivity ( $E$ and $S)$, exposure and sensitivity and adaptive capacity $(E, S$, and $\mathrm{AC})$, or could not be classified (unclassified).

Note: Only a portion of the surveyed projects pertained to a focal resource or a focal threat and the sum for each category is, therefore, less than 124.

\begin{tabular}{|c|c|c|c|c|c|c|c|c|c|c|c|c|}
\hline & \multicolumn{6}{|c|}{ Focal resources } & \multicolumn{6}{|c|}{ Focal climate-related threats } \\
\hline & $\begin{array}{l}\text { Freshwater } \\
\text { supplies }\end{array}$ & $\begin{array}{c}\text { Landscapes/ } \\
\text { wildlife } \\
\text { habitat }\end{array}$ & $\begin{array}{c}\text { Native } \\
\text { and } \\
\text { cultural } \\
\text { resources }\end{array}$ & $\begin{array}{l}\text { Ocean } \\
\text { health }\end{array}$ & $\begin{array}{c}\text { More } \\
\text { than } 1 \\
\text { focal } \\
\text { resource }\end{array}$ & Total & $\begin{array}{l}\text { Invasive } \\
\text { species }\end{array}$ & $\begin{array}{l}\text { Wildfire } \\
\text { risk }\end{array}$ & $\begin{array}{c}\text { Sea- } \\
\text { level } \\
\text { rise }\end{array}$ & $\begin{array}{c}\text { Melting } \\
\text { ice/permafrost }\end{array}$ & $\begin{array}{c}\text { More } \\
\text { than } 1 \\
\text { focal } \\
\text { threat }\end{array}$ & Total \\
\hline $\mathbf{E}$ & 24 & 4 & 0 & 0 & 6 & 34 & 1 & 0 & 7 & 0 & 1 & 9 \\
\hline $\mathbf{S}$ & 1 & 5 & 0 & 0 & 2 & 8 & 0 & 1 & 0 & 0 & 1 & 2 \\
\hline$E$ and $S$ & 0 & 26 & 0 & 1 & 7 & 34 & 5 & 0 & 11 & 1 & 7 & 24 \\
\hline $\mathrm{E}, \mathrm{S}$, and $\mathrm{AC}$ & 0 & 34 & 1 & 2 & 4 & 41 & 0 & 4 & 29 & 0 & 1 & 34 \\
\hline Unclassified & 0 & 3 & 0 & 0 & 2 & 5 & 0 & 0 & 0 & 0 & 1 & 1 \\
\hline Total & 25 & 72 & 1 & 3 & 21 & 122 & 6 & 5 & 47 & 1 & 11 & 70 \\
\hline
\end{tabular}




\section{Appendix A. Text distributed to DOI agencies for the initial data call on climate change vulnerability assessments.}

\section{DATA CALL - CLIMATE CHANGE VULNERABILITY ASSESSMENTS \\ Definitions:}

Vulnerability is the degree to which a natural or human system is susceptible to, and unable to cope with, adverse effects of climate change, including climate variability and extremes.

Vulnerability is a function of the character, magnitude, and rate of climate change and variation to which a system is exposed, its sensitivity, and its adaptive capacity.

Vulnerability assessments are science-based activities (research, synthesis, modeling, monitoring) undertaken with the intent of identifying, quantifying, or evaluating the degree to which natural resources, cultural resources, infrastructure, or other values are likely to be affected by changing climatic conditions. Each vulnerability assessment minimally needs to address each of the following factors for one or more systems in the area being assessed:

$>$ Sensitivity of the resources in question to climate change

$>$ Likely exposure of the resources in question to climate change

$>$ Adaptive capacity of the resources in question to climate change

Theses assessments should include considerations of current and future potential vulnerabilities. The focus of a vulnerability assessment can be a specific resource or resource type (e.g., species, cold water fish), sector (e.g., fresh water, energy, forestry), community (e.g., city, ecosystem), site (town, refuge, park), region (e.g., state, southwestern deserts), or other assessment target. The level of detail and comprehensiveness will vary with management needs and consequences, available resources, and the state of knowledge. An assessment consists of a report evaluating resource vulnerability, or any combination of a stand-alone report, data sets, and/or results and analyses.

Individual vulnerability assessments may be undertaken at a range of geographic scales and may address individual species or ecosystem elements, or one or more systems consistent with the mission of the respective bureau and any non-federal partners, with the goal of identifying the vulnerabilities affecting the assessment target, or may be done to evaluate relative vulnerabilities of multiple targets across a geographic area.

\section{Information Requested:}

Each bureau is requested to provide to ClimateHPPG@usgs.gov, for collection and "mapping" and comparison with LCC coverage, the following:

1. The number of vulnerability assessments underway per each quarter in FY 2011 and then FY 2012

2. The number of vulnerability assessments completed per each quarter in FY 2011 and then FY 2012 
For each of the assessments identified, please provide the following information. For planning purposes, please assume funding levels for FY 2011 and FY 2102 that are equivalent to that provided in the FY 2011 President's Budget Request to Congress.

1. Project location. Please provide adequate information to enable mapping of the geographic extent / area and location (especially relative to the coverage of each Landscape Conservation Cooperative) addressed by the project.

2. Assessment endpoints. Please describe what resources are being assessed against which threats for vulnerability to climate change. Where applicable, identify which of the focal resources are being assessed against which of the focal threats that are identified in the DOI HPPG. (Please note that there are no definitions of the terms for the HPPG focal threats and resources; please use common sense and your best judgment.)

a. DOI High Priority Performance Goal (HPPG) Focal Resources

- fresh water supplies

- landscapes, including wildlife habitat

- native and cultural resources

- ocean health

b. DOI High Priority Performance Goal (HPPG) Focal Threats

- invasive species

- wildfire risk

- sea-level rise

- melting ice/permafrost

c. Other Resources and Threats

While these focal resources and threats were identified in the Priority Goal, please be sure to specify any other resources and threats that are part of the main purpose of the assessment under "other" resources or "threats" in the attached template. 


\section{Appendix B. Questionnaire used for the supplemental DOI vulnerability assessment survey.}

1. What are the objectives of your Vulnerability Assessment?

2. What is your assessment target (e.g., species, habitat, ecosystem, ecosystem service)?

3. Where is your Vulnerability Assessment located?

4. What is the size of your study area?

5. How did you go about assessing vulnerability of your target (e.g., sensitivity, exposure, and adaptive capacity)?

6. Did you use downscaled climate projections? If so, can you describe briefly what you used and who generated them?

7. Can you briefly describe the ecological response model you used (e.g., NatureServe index, climate envelope model)? 
ISSN 2331-1258 (online)

http://dx.doi.org/10.3133/ofr201511 